\title{
Anaesthesia in Elective Surgery and its Outcome
}

\author{
Dr. Sanjay Khot ${ }^{1}$, Dr. S. R. Verma ${ }^{* 2}$ \\ ${ }^{1}$ Assistant Professor, ${ }^{* 2}$ Associate Professor \\ Department of Anaesthesiology Chandulal Chandrakar Memorial Medical College, \\ Kachandur, Durg (Chhattisgarh) 490024
}

\section{Address for Correspondence}

Dr. S. R. Verma

Associate Professor Dept. of Anaesthesiology

Chandulal Chandrakar Memorial Medical College, Kachandur, Durg (Chhattisgarh) Pin code-490024

\section{Introduction}

Anaesthesia is classified into two main techniques general anaesthesia (GA) in which gaseous and/or intravenous drugs achieve central neurological depression, and regional anaesthesia, in which drugs are administered directly to the vicinity of spinal cord or nerves to locally block afferent and efferent nerves. ${ }^{[1]}$

The anaesthesiologist is the medical specialists who can evaluate the risk associated with the anaesthesia discuss these risks with the patient and surgeon to manage them intraoperative. Now a day anesthesia is no longer limited to the operation room but it a perioperative care. ${ }^{[2]}$ The presence of comorbid conditions in surgical patients is significant factors in preoperative morbidity and mortality risk assessment. ${ }^{[3]}$ The current practices in anesthesia include complete valuation of risks, control costs, allocate resources, and postpone surgery until interventions improve risk. $^{[4]}$

The risks of fatal or life threatening events are increased several fold in the patients with comorbidities after major surgery. Systemic comorbidities such as pulmonary, cardiovascular, hepatic and metabolic diseases and cancers which modify treatment tolerance and influence short-term prognosis. $^{[5]}$

Various instruments have been developed to assess the effect of comorbidities on patient survival after surgery. ${ }^{[6]}$ For head and neck cancers Adult Comorbidity Evaluation Index (ACE-27) has been widely validated. ${ }^{[7]}$

\section{Aims and Objectives}

Aim of this prospective study was to determine the frequencies of comorbidities in elective surgical patients operated in our hospital and its effects on the outcome of anaesthesia and identify variables for future studies.

\section{Material and Methods}

This is an observational, prospective study of a crosssection. Adult patients $>18$ years were selected for the study who were posted for the elective surgery. Study was carried out in the department of anaesthesia CCM Medical College and hospital from Feb 2018 to May 2018.

Written consent was taken from the patients who were included in the study. The protocol was approved by the Clinical Research Ethical Committees. All comorbidities of the patients were recorded and also ensured they were controlled and fit for anesthesia and surgery. Patient's demographic data like age, sex, medications, presence and type of comorbidities were recorded in a standardized format. Other information was retrieved from the patients' medical record. For hypertensive patients antihypertensive were continued till morning of the surgery except amlodipine which was omitted on the morning of surgery because of significant drop of blood pressure as reported by some authors. For diabetic patients on insulin infusion up to morning of surgery was given.

Intraoperative and immediate postoperative complications were recorded in a separate data collection form. Various parameters were monitored like continuous electrocardiogram, heart rate, non-invasive blood pressure, and arterial oxygen saturation. Hypertension defined as diastolic pressure $>110 \mathrm{mmHg}$ or systolic pressure $>140$ $\mathrm{mmHg}$ and hypotension defined as systolic arterial blood pressure of $80 \mathrm{mmHg}$ or less .The patients were also followup for 24 hours postoperatively and record of adverse effect was kept like vomiting, shivering, pain etc.

\section{Statistical Analysis}

The data were analysed using Windows Excel 2013. Results are represented in means \pm standard deviation and using tables. $\mathrm{Z}$ test was used to determine the difference of 
proportion between the presence and absence of comorbidity and adverse events. $\mathrm{P} \leq 0.05$ was regarded as being significant.

\section{Results}

Table 1: comorbidities in the patients for elective surgery

\begin{tabular}{|l|c|c|}
\hline Comorbidities & $\boldsymbol{n}$ & $\%$ \\
\hline Hypertension & 26 & 50.98 \\
\hline Diabetes mellitus & 16 & 31.37 \\
\hline Anemia & 4 & 7.84 \\
\hline Asthma & 2 & 3.92 \\
\hline Heart disease & 2 & 3.92 \\
\hline Rheumatoid arthritis & 1 & 1.96 \\
\hline Total & 51 & \\
\hline
\end{tabular}

In our study out of 124 patients selected for elective surgery 51 patients were having one or more comorbid condition. Out of $51(41.13 \%)$ patients with comorbidity in 26 patients hypertension was observed. In $16(31,37 \%)$ cases diabetes was present as a comorbid condition. 2 (3.92\%) patients
There were 694 elective surgeries during the study period, however only 124 patients were included in the study. Out of 124 selected patients 51 patients were having comorbidities. In our study rate of patients with comorbidities was found to be $124 / 51(41.12 \%)$ each, were having asthama and heart disease and one patient $(1.96 \%)$ was having rheumatoid arthritis.

Mean age of the patients posted for elective surgery in our study was $47.4 \pm 7.4 \mathrm{SD}$ (Standard deviation) while patients with co morbidities mean age was $56 \pm 6.1$ SD.

Table 2: Surgical procedures in patients with and without comorbidities

\begin{tabular}{|l|c|c|c|c|}
\hline & $\begin{array}{c}\text { Patients without co-morbidities } \\
(\mathbf{n = 1 2 4})\end{array}$ & \% & $\begin{array}{c}\text { Patients with co- } \\
\text { morbidities (n= 51) }\end{array}$ & $\begin{array}{c}\text { \% } \\
\text { Procedure }\end{array}$ \\
\hline General surgery & 59 & 47.58 & 24 & 47.06 \\
\hline Orthopedic surgery & 28 & 22.58 & 11 & 21.57 \\
\hline Gynecological & 27 & 21.77 & 10 & 19.61 \\
\hline ENT surgery & 10 & 8.06 & 6 & 11.76 \\
\hline
\end{tabular}

Maximum patients with and without co morbidities were operated in general surgery department in both group percentage was $47 \%$. In orthopaedic department patients without comorbidities operated were $28(22.58 \%)$ while Patients with co-morbidities was 11 (21.57\%). In

Table 3: Type of anaesthesia

\begin{tabular}{|c|c|c|c|c|}
\hline Type of anaesthesia & $\begin{array}{l}\text { Patients without co- } \\
\text { morbidities }(n=124)\end{array}$ & $\%$ & $\begin{array}{c}\text { Patients with co- } \\
\text { morbidities }(\mathrm{N}=51)\end{array}$ & $\%$ \\
\hline General anaesthesia & 71 & 57.26 & 22 & 43.14 \\
\hline Spinal anaesthesia & 15 & 12.10 & 10 & 19.61 \\
\hline peripheral nerve block & 13 & 10.48 & 6 & 11.76 \\
\hline Combined spinal and epidural anaesthesia & 25 & 20.16 & 13 & 25.49 \\
\hline
\end{tabular}

General anaesthesia was given to $71(57.26 \%)$ patients without comorbidities while in patients with comorbidities it was $22(43.14 \%)$. Spinal anaesthesia in patients without and with comorbidities was $15(12.10 \%)$ and 10 (19.61\%) respectively. Combined spinal and epidural anaesthesia in department of Gynaecology patients without and with comorbidities were $27(21.77 \%)$ and $10 \quad(19.61 \%)$ respectively. In ENT department patients without and with comorbidities were $10(8.06 \%)$ and $6(11.76 \%)$ respectively.

Table 4: Intraoperative adverse effects observed in patients

\begin{tabular}{|l|c|c|c|c|c|}
\hline Adverse effects & $\begin{array}{c}\text { Patients without co- } \\
\text { morbidities }\end{array}$ & $\boldsymbol{\%}$ & $\begin{array}{c}\text { Patients with co- } \\
\text { morbidities }\end{array}$ & $\boldsymbol{\%}$ & P value \\
\hline None & 116 & 93.55 & 30 & 58.82 & $<0.00$ \\
\hline Hypertension & 2 & 1.61 & 5 & 9.80 & 0.01 \\
\hline Tachycardia & 1 & 0.81 & 3 & 5.88 & 0.04 \\
\hline
\end{tabular}


International Journal of Innovative Research in Medical Science (IJIRMS)

Volume 03 Issue 05 May 2018, ISSN No. - 2455-8737

Available online at - www.ijirms.in

\begin{tabular}{|l|l|l|l|l|c|} 
Nausea & 1 & 0.81 & 3 & 5.88 & 0.04 \\
\hline Vomiting & 2 & 1.61 & 5 & 9.80 & 0.01 \\
\hline Hypotension & 0 & 0.00 & 4 & 7.84 & 0.00 \\
\hline Delayed recovery & 2 & 1.61 & 1 & 1.96 & Not significant \\
\hline
\end{tabular}

In $116(93.55 \%)$ patients without comorbidities no adverse effect was observed during surgery. While in patients with co-morbidities nil adverse effect was observed during surgery was $30(58.82 \%)$.

Hypertension was observed in 2 (1.61\%) and 5 (9.80\%) cases in without comorbidities and with co-morbidities respectively. Tachycardia and nausea was observed each in $1(0.81 \%)$ and $3(5.88 \%)$ cases without comorbidities and with co-morbidities respectively. Vomiting was seen in 2 $(1.61 \%)$ and $5(9.80 \%)$ cases without comorbidities and with co-morbidities respectively Hypotension was not observed in any case without comorbidity while in patients with comorbidities it was $4(7.84 \%)$. Delayed recovery was observed in $2(1.61 \%)$ and $1(1.96 \%)$ of the cases without comorbidities and with co-morbidities.

\section{Discussion}

Risk assessment is necessary to compare outcomes, postpone surgery until risk factors are improved or to take the decision not to perform the surgery or unfit for anaesthesia when the risk is very high. ${ }^{[10]}$ Disease-specific comorbidity measures have a advantage but the outcome may not be as predicted as proposed in a study of conceptual models in health services. ${ }^{[11]}$

The presence of comorbidity is a major prognostic factor but the underlying mechanisms are not well understood. So it is worthwhile to identify the single diseases contributing to the risk of complications so that predisposing factors for post-operative morbidity can be avoided. ${ }^{[12]}$

Comorbidities associated with surgical pathologies in our study was $41.13 \%$ which was quite higher as compared to the study by Eyelade O. et al[13] in which they observed the rate of $27.3 \%$, while Soyannwo OA.et al ${ }^{[14]}$ observed $9.2 \%$ comorbidities. The reason may be due to increased prevalence of diabetes and hypertension in India which was shown to be $7.5 \%$ (95\% CI, 7.3\%-7.7\%) and $25.3 \%$ (95\% CI, $25.0 \%-25.6 \%$ ), respectively in a study. ${ }^{[15]}$

Hypertension was the most common comorbidity in this study similar results were shown by Haq ZA etal.[16] in their study, also in a study at Africa hypertension was the commonest comorbid condition. ${ }^{[17]}$

All the patients were well controlled with medications for their comorbid conditions, 10 surgeries were postponed due to patients with uncontrolled hypertension so as to reduce the perioperative risk. Also inprean aesthetic check-up other parameters were checked like electrolyte, urea, creatinine, an electrocardiogram to exclude other organ damage.
We observed statically significant hypotension, hypertension, and tachycardia in patients with comorbidities. In the course of anaesthetic management of patients with hypertension, the continuation of antihypertensive medication throughout the preoperative period was done to reduce the risk of uncontrolled hypertension still in $5(9.8 \%)$ cases with comorbidities hypertension was observed preoperatively .Some authors have reported severe postoperative hypotension with use of amlodipine. $^{[18]}$ Due to increase in the prevalence of hypertension in our area patients with comorbidities as diabetes was high in our study.

Diabetes mellitus is the second common comorbidity identified. Altered gluco regulation is an established risk factor predisposing to various complications such as impaired wound healing, endothelial dysfunction, postoperative sepsis, in surgical patients. Sometimes there may be diabetic ketoacidosis and hyperglycaemic hyperosmolar state. Stress during surgery and anaesthesia might aggravate the pre-existing deranged gluco regulation and may precipitate severe hyperglycaemia which leads to postoperative morbidity and mortality. ${ }^{[19]}$ Anaesthesia and surgery cause metabolic stress which will release of the catabolic hormones epinephrine, norepinephrine, cortisol, glucagon and growth hormone. Insulin secretion and action are however inhibited. ${ }^{[20]}$ In our study sixteen (31.37\%) patients were having diabetes as comorbidity. Preoperative glycemic control was achieved by insulin infusion. This infusion is also useful in low resource setting area. ${ }^{[21]}$

In our study we observed that most of the patients with adverse effects had general anaesthesia. Some authors have recommended the use of local or regional anaesthesia in patients with comorbidities to avoid the polypharmacy of general anesthesia. ${ }^{[22]}$ However in regional anaesthesia complication like hypotension was observed in patients with comorbidities.

Significant difference was observed between adverse effects in patients with comorbidities and without comorbidities. Statistically significant difference was observed in hypertension, tachycardia, and nausea and vomiting.

\section{Conclusion}

In our study hypertension is the commonest comorbidity. The presence of comorbidity has influences on the adverse effects of anaesthesia in this study. Our sample size was small so further studies are required to be carried out to determine the impact of comorbidity in patients. 
Financial support and sponsorship - Nil

Conflicts of interest - There are no conflicts of interest.

\section{References}

[1] Cousins M, Bridenbaugh P, editors. Neural blockade in clinical anesthesia and management of pain. 2nd ed. Philadelphia: J B Lippincott; 1988.

[2] Bader AM, Sweitzer BJ. Preoperative evaluation. In: Miller RD, editor. Millers Anaesthesia. 7th ed. Philadelphia: Churchill Livingstone; 2010. pp. 1001-37.

[3] Thomas M, George NA, Gowri BP, George PS, Sebastian $P$ Comparative evaluation of ASA classification and ACE-27 index as morbidity scoring systems in oncosurgeries. Indian J Anaesth. 2010 May; 54(3):219-25.

[4] Rossi M, Iemma D. Patients with comorbidities: what shall we do to improve the outcome. Minerva Anestesiol. 2009 May; 75(5):325-7.

[5] Sanabria A, Carvalho AL, Vartanian JG, Magrin J, Ikeda MK, Kowalski LP Comorbidity is a prognostic factor in elderly patients with head and neck cancer. Ann Surg Oncol. 2007 Apr; 14(4):1449-57.

[6] Piccirillo JF, Lacy PD, Basu A, Spitznagel EL Development of a new head and neck cancerspecific comorbidity index. Arch Otolaryngol Head Neck Surg. 2002 Oct; 128(10):1172-9.

[7] Piccirillo JF Importance of comorbidity in head and neck cancer. Laryngoscope. 2000 Apr; 110(4):593-602.

[8] Kadam PG, Jayaprakash, Shah VR. Postoperative hypotension associated with amlodipine. Middle East J Anaesthesiol. 2013; 22:113-6.

[9] Bijker JB, van Klei WA, Kappen TH, van Wolfswinkel L, Moons KG, Kalkman CJ. Incidence of intraoperative hypotension as a function of the chosen definition: Literature definitions applied to a retrospective cohort using automated data collection. Anesthesiology. 2007; 107:213-20.

[10] Bader AM, Sweitzer BJ. Preoperative evaluation. In: Miller RD, editor. Millers Anaesthesia. 7th ed. Philadelphia: Churchill Livingstone; 2010. pp. 1001-37.

[11] Geraci JM, Escalante CP, Freeman JL, Goodwin JS. Comorbid disease and cancer: The need for more relevant conceptual models in health services research. J ClinOncol. 2005; 23:7399-401.

[12] Mary Thomas, Nebu Abraham George, Balagopal Prabhakar Gowri, Preethi Sara George, Paul Sebastian. Comparative evaluation of ASA classification and ACE-27 index as morbidity scoring systems in oncosurgeries. Indian $\mathbf{J}$ Anaesth. 2010 May-Jun; 54(3): 219-225
[13] Olayinka Eyelade, Arinola Sanusi, Tinuola Adigun, and Olufemi Adejumo. Outcome of anesthesia in elective surgical patients with comorbidities. Ann Afr Med. 2016 Apr-Jun; 15(2): $78-82$

[14] Soyannwo OA, Bamgbade OA, Odutola OO. Medical diseases and anaesthesia. Afr J Anaesth Intensive Care. 1996; 2:51-6.

[15] Geldsetzer P, Manne-Goehler J, Theilmann M, Davies JI, Awasthi A, Vollmer S, Jaacks LM, Bärnighausen T, Atun R. Diabetes and Hypertension in India: A Nationally Representative Study of 1.3 Million Adults. JAMA Intern Med. 2018 Mar 1;178(3):363-372

[16] Haq ZA, Murthy P, Malik I, Lahori VU, Chaudhary S, Ahuja S. Detection of comorbid illnesses during preanaesthesiaevaluation in a university teaching hospital: A prospective observational study. Natl Med J India. 2014 Sep-Oct;27(5):256-8

[17] Edomwonyi NP, Imarengiaye CO. Intercurrent medical diseases: Incidence and effects on the course of anaesthesia in a tertiary hospital. Niger Postgrad Med J. 2006; 13:75-80.

[18] Parida S, Nawaz M, Kundra P. Severe hypotension following spinal anesthesia in patients on amlodipine. J Anaesthesiol Clin Pharmacol. 2012; 28:408-9.

[19] Rudrashish Haldar, Ankur Khandelwal, Devendra Gupta, Shashi Srivastava, and Prabhat K Singh. Acute post-operative diabetic ketoacidosis: Atypical harbinger unmasking latent diabetes mellitus. Indian J Anaesth. 2016 Oct; 60(10): 763765.

[20] Samuel DJ, Alberti KG. Management of diabetes mellitus in surgical patients. Diabetes Spectrum. 2002; 15:44-8. [

[21]Bolaji BO. Peri-operative blood glucose control using glucose-potassium-insulin infusion: Report of 2 cases. Trop J Health Sci. 2004; 11:45-9.

[22] O'Hara DA, Duff A, Berlin JA, Poses RM, Lawrence VA, Huber EC, et al. The effect of anesthetic technique on postoperative outcomes in hip fracture repair. Anesthesiology. 2000; 92:94757. 